\title{
Red Cell Volume Can Be Accurately Determined in Sheep Using a Nonradioactive Biotin Label
}

\author{
DONALD M. MOCK, NELL I. MOCK, GARY L. LANKFORD, LEON F. BURMEISTER, RONALD G. STRAUSS, \\ AND JOHN A. WIDNESS
}

\begin{abstract}
Department of Biochemistry \& Molecular Biology [D.M.M., N.I.M., G.L.L.], Department of Pediatrics [D.M.M.], University of Arkansas for Medical Sciences, Little Rock, Arkansas, 72205; Department of Biostatistics [L.F.B.], Department of Pathology [R.A.S.],
\end{abstract} Department of Pediatrics [R.A.S., J.A.W.], University of Iowa, Iowa City, Iowa, 52242

\begin{abstract}
The sheep has served as an informative animal model for investigation of human fetal and newborn erythropoiesis and red blood cell (RBC) kinetics. We previously validated the permanent label $\left({ }^{14} \mathrm{C}\right)$ cyanate for measuring red cell volume (RCV) in sheep. Here, we validate biotin labeling of RBCs as a nonradioactive method for measuring RCV in sheep with the anticipation that it can be applied in studies of human infants. The RCV was determined simultaneously using two techniques for quantitation of the biotin label. The first one quantified total blood concentration of biotin label on biotin-labeled RBCs using $\left({ }^{125} \mathrm{I}\right)$ streptavidin. The second one enumerated biotin-labeled RBCs by flow cytometry after incubation with fluorescein-conjugated avidin. RCV measurements made using the two biotin quantitation techniques were validated against both $\left({ }^{14} \mathrm{C}\right)$ cyanate and ${ }^{51} \mathrm{Cr}$ as reference methods. Both biotin techniques produced RCV values that agreed well with the reference methods and with each other, producing correlation coefficients averaging $\geq 0.93$. Sequential repetitive measurements in the same animal also agreed with the $\left({ }^{14} \mathrm{C}\right)$ cyanate method and each other (average difference $<10 \%$ ). These results establish biotin-labeled RBCs as an accurate method for performing RCV measurements in sheep. This biotin method can be applied in studies that model neonatal erythropoiesis. (Pediatr Res 64: 528-532, 2008)
\end{abstract}

$\mathrm{W}$ ith the consensus among the scientific community in the late 1960s that the use of radioactive materials was ethically untenable in research studies of fetuses, neonates, and pregnant women, the rate of progress in understanding red blood cell (RBC) kinetics and RBC volume in the perinatal period has nearly come to a halt (1). Yet, the need for understanding has continued to accelerate. Advances in obstetrics and in fetal medicine now permit intrauterine fetal blood sampling, transfusion, and other therapies to be delivered directly into the fetal circulatory system. Advances in neonatal medicine during this period include neonatal therapies that have resulted in improved survival and outcomes of extremely low birth weight $(<1 \mathrm{~kg})$ and other critically ill infants (2). Although substantial evidence supports the use of surfactant, improved ventilator support, inhaled nitric oxide, and extracorporeal membrane oxygenation, other treatments

Received February 25, 2008; accepted May 29, 2008.

Correspondence: Donald M. Mock, M.D., Ph.D., Slot \#516, Department of Biochemistry \& Molecular Biology, University of Arkansas for Medical Sciences, 4301 W Markham Street, Little Rock, AR 72205; e-mail: MockDonaldM@uams.edu

Supported by the National Heart, Lung, and Blood Institute via Grant NIH P01 HL046925.

Supplementary material available online at www.pedresearch.org. such as erythropoietin and autologous placental blood for transfusion have weaker supporting bases of evidence and are being actively investigated.

Reliable methods for measuring red blood cell volume $(\mathrm{RCV})$ and survival in the pregnant woman, fetus, and infant are needed to further our understanding of the physiology and pathophysiology of a variety of perinatal conditions and their responses to treatment. Concerns about radiation effects have motivated the development of a practical method that does not expose infants, children, and pregnant women to radioactivity. RCV methods have been published that use stable isotopes followed by neutron activation (3) or x-ray fluorescence (4), but these methods require highly specialized, expensive equipment $(3,4)$, are not sufficiently sensitive for the small volumes of blood available from neonates (4), or both. As a result, neither of these methods has gained widespread use.

The biotin RBC labeling method using either ex vivo $\left({ }^{125} \mathrm{I}\right)$ streptavidin quantitation or flow cytometry enumeration is sufficiently sensitive (5-7) for use in determining RCV and RBC survival in neonates and adults without exposure to radiation. In addition, biotinylation reagents are commercially available $(5,7)$, and the equipment required is available in most medical center clinical laboratories $(5,7)$. Technician time required for analysis is modest.

Because ovine fetal and newborn cardiovascular, pulmonary, and hematologic development resembles human physiology, the sheep model has been commonly used for preclinical studies. In particular, ovine erythropoiesis in the fetus, neonate, and adult is similar to the human; accordingly, regulation of erythropoiesis and $\mathrm{RBC}$ kinetics in the ovine model are currently areas of active study (8-11).

An accurate, validated, practical method for determining $\mathrm{RCV}$ in the sheep would be useful for investigating neonatal anemia and cardiovascular problems. We previously demonstrated that the permanent $\mathrm{RBC}$ label $\left({ }^{14} \mathrm{C}\right)$ cyanate is a valid alternative to ${ }^{51} \mathrm{Cr}$ for measuring RCV in sheep (12). However, radioactive contamination presents a substantial disposal cost and $\left({ }^{14} \mathrm{C}\right)$ cyanate is no longer commercially available. ${ }^{51} \mathrm{Cr}$ is commercially available but is not suitable for $\mathrm{RBC}$ survival studies in sheep because $\mathrm{Cr}$ elutes from sheep RBCs over a few days. ${ }^{51} \mathrm{Cr}$ also presents substantial disposal costs

Abbreviations: RBC, red blood cell; RCV, red cell volume 
associated with the radioactive contamination of the animal and its excretion products. Thus, the objective of this study was to validate the use of the biotin labeling of RBCs and quantitation with both $\left({ }^{125} \mathrm{I}\right)$ streptavidin detection and flow cytometry enumeration as alternative techniques for measuring $\mathrm{RCV}$ in sheep.

\section{METHODS}

These studies were approved by the Institutional Animal Care and Use Committee of the University of Arkansas for Medical Sciences.

Red blood cell labeling procedures. The method validated here for the measurement of RCV is based on biotinylation of RBC surface proteins, reinfusion of the biotin-labeled RBCs, and quantitation of the biotin label in blood samples taken from the peripheral circulation. For this study, two techniques for quantitation of the biotin-labeled RBCs were used. In the first technique, the RBCs from venous blood are incubated with $\left({ }^{125}\right.$ I)streptavidin; the ${ }^{125} \mathrm{I}$ bound to the RBCs is a measure of the blood concentration of the biotin label. Conceptually and mathematically, this technique parallels the RCV techniques based on blood concentration of $\left({ }^{14} \mathrm{C}\right)$ cyanate or ${ }^{51} \mathrm{Cr}$.

The second technique utilizes flow cytometry to enumerate biotin-labeled RBCs in the venous blood sample after incubation of the blood with fluorescein-conjugated avidin. This technique determines labeled RBCs as a percent of total cells rather than as the blood concentration of the biotin label. The flow cytometry technique offers the advantage over the $\left({ }^{125} \mathrm{I}\right)$ streptavidin technique and the ${ }^{51} \mathrm{Cr}$ and $\left({ }^{14} \mathrm{C}\right)$ cyanate methods of not being susceptible to concentration ("sludging") and dilution ("squeezing") blood sample artifacts encountered with capillary blood sampling frequently performed in newborns $(13,14)$

The technical details of the methods for determination of RCV in sheep using $\left({ }^{14} \mathrm{C}\right)$ cyanate or ${ }^{51} \mathrm{Cr}$ method have been published (12). Only minor modifications used in the studies reported here are provided in the Appendix (supplemental material available online at www.pedresearch.org). Likewise, the biotin method with quantitation using either the $\left({ }^{125} \mathrm{I}\right)$ streptavidin technique or the flow cytometry technique have been published for human RBCs (5). Because the method for labeling sheep RBCs with biotin has not been published, the differences from the method for human RBCs have been included in the Appendix (online at www.pedresearch.org). The modifications for sheep $\mathrm{RBCs}$ are required principally because sheep RBCs are approximately one-third the volume of human RBCs.

A rough estimate of each sheep's RCV and blood volume was needed to calculate amounts of biotinylation reagent, $\left({ }^{14} \mathrm{C}\right)$ cyanate, and ${ }^{51} \mathrm{Cr}$. This estimate was made using a reference RCV per $\mathrm{kg}$ of $19 \mathrm{~mL} / \mathrm{kg}$. A similar reference value had been previously found by our group (12) using $\left({ }^{14} \mathrm{C}\right)$ cyanate as $18.8 \pm 3.8$ $\mathrm{mL} / \mathrm{kg}$ (mean $\pm 1 \mathrm{SD}$ ). This value for RCV per kg agreed very well with our value determined in the same sheep using the ${ }^{51} \mathrm{Cr}$ method of $18.8 \pm 3.9$ $\mathrm{mL} / \mathrm{kg}$. In addition to the within-study agreement in the previously published study (12), the RCV per kg values measured in that study using $\left({ }^{14} \mathrm{C}\right)$ cyanate and ${ }^{51} \mathrm{Cr}$ methods agreed reasonably well with the value of $21.1 \pm 2.2 \mathrm{~mL} / \mathrm{kg}$ determined by Wade and Sasser in a different population of sheep using both ${ }^{59} \mathrm{Fe}$ and ${ }^{51} \mathrm{Cr}$ (15). Blood volume estimate was calculated from the RCV and the hematocrit.

Labeling and infusion of red blood cells labeled with $\left({ }^{14} \mathrm{C}\right)$ Cyanate, ${ }^{51} \mathrm{Cr}$, and biotin. Approximately $2 \%$ of the sheep's total blood volume was withdrawn from the external jugular by venipuncture on the day of study. The sheep's RCV and blood volume were estimated as described above. Separate RBC aliquots were labeled with $\left({ }^{14} \mathrm{C}\right)$ cyanate, ${ }^{51} \mathrm{Cr}$, and biotin. The labeling efficiency averaged about $30 \%$ for the $\left({ }^{14} \mathrm{C}\right)$ cyanate method, about $4 \%$ for ${ }^{51} \mathrm{Cr}$ method, and about $2 \%$ for biotin labeling. The volumes of the $\left({ }^{14} \mathrm{C}\right) \mathrm{cy}-$ anate, ${ }^{51} \mathrm{Cr}$, and biotin-labeled RBCs were adjusted by addition of the sheep's autologous plasma to a hematocrit approximately equal to that of the original blood and mixed together in a sterile syringe. The labeled mixture was then infused into the sheep through a catheter inserted into the external jugular vein. Infusion of the entire volume of label was accomplished in 1 to $2 \mathrm{~min}$. Total radioactivity infused for ${ }^{51} \mathrm{Cr}$ and $\left({ }^{14} \mathrm{C}\right)$ cyanate were calculated from radioactivity per $\mathrm{mL}$ of the final infusate mixture multiplied by the volume of the mixture infused. The volume was determined gravimetrically by weight difference of the syringe before and after infusion. For RCV determination, four to five samples ( $7 \mathrm{~mL}$ each) were drawn between 2 and $30 \mathrm{~min}$ following infusion of the labeled RBCs.

${ }^{14} \mathrm{C}$ assay. Radioactivity of ${ }^{14} \mathrm{C}$ per $\mathrm{mL}$ of blood was assayed by the acid acetone technique. In this method, heme is decolored and extracted from globin using acidification and acetone precipitation. ${ }^{14} \mathrm{C}$ bound to the globin is quantitated by liquid scintillation using a Packard Tri-Carb LSC (16). The intra-assay coefficient of variation for quadruplicate measurements was $<2 \%$.

${ }^{51} \mathrm{Cr}$ assay. Quantitation of the ${ }^{51} \mathrm{Cr}$ radioactivity per $\mathrm{mL}$ of blood was by gamma counting using energy windows of 0 to $1000 \mathrm{keV}$. The intra-assay coefficient of variation for quadruplicate measurements was $<3 \%$.

Assay for biotin label concentration using $\left({ }^{125}\right.$ I)streptavidin. $\left({ }^{125} \mathrm{I}\right)$ streptavidin was mixed with the blood samples and incubated for $1 \mathrm{~h}$ at $5{ }^{\circ} \mathrm{C}$ to allow the avidin to bind to biotinylated RBCs. After the incubation, the biotinylated $\mathrm{RBCs}$ and bound $\left({ }^{125} \mathrm{I}\right)$ streptavidin were separated from the excess free $\left({ }^{125} \mathrm{I}\right)$ streptavidin by dextran-metrizoic acid density centrifugation. Bound $\left({ }^{125}\right.$ I)streptavidin of standards and sheep in vivo samples were determined by gamma counting. The background radiation from ${ }^{51} \mathrm{Cr}$ was $\leq 3 \%$ of the total $\mathrm{cpm}$ of $\left({ }^{125} \mathrm{I}\right)$ streptavidin and was subtracted. A standard curve was constructed using biotin-labeled RBCs diluted in unlabeled RBCs. Intra-assay coefficient of variation for quadruplicate measurements was $<2 \%$. See Appendix (online at www.pedresearch.org) for additional details.

Assay of biotin label using flow cytometry technique. Each of the samples from the standard curve prepared as described above and the postinfusion samples were incubated with fluorescein-labeled avidin for $30 \mathrm{~min}$. Unbound fluorescein-labeled avidin was removed by washing as described previously (5). The fluorescein-avidin:biotin-labeled RBCs were enumerated by flow cytometry. Figure $1 A$ (supplemental material online at www.pedresearch.org) depicts the RBC region selected ("gated") using a plot of side scatter ( $y$ axis) versus forward scatter ( $x$ axis). Figure $1 B$ (supplemental material online at www.pedresearch.org) depicts a histogram of the number of RBCs detected versus the $\log$ of fluorescent intensity per RBC ( $x$ axis) for a mixture of labeled and unlabeled RBCs that has an enrichment typical of the 1 to $2 \%$ ratio of labeled to unlabeled RBCs used in the sheep studies reported here. The density of biotin used in labeling RBCs was chosen to achieve a substantial separation in the histogram of biotin labeled RBCs and unlabeled RBCs. See Appendix (online at www.pedresearch.org) for more detail.
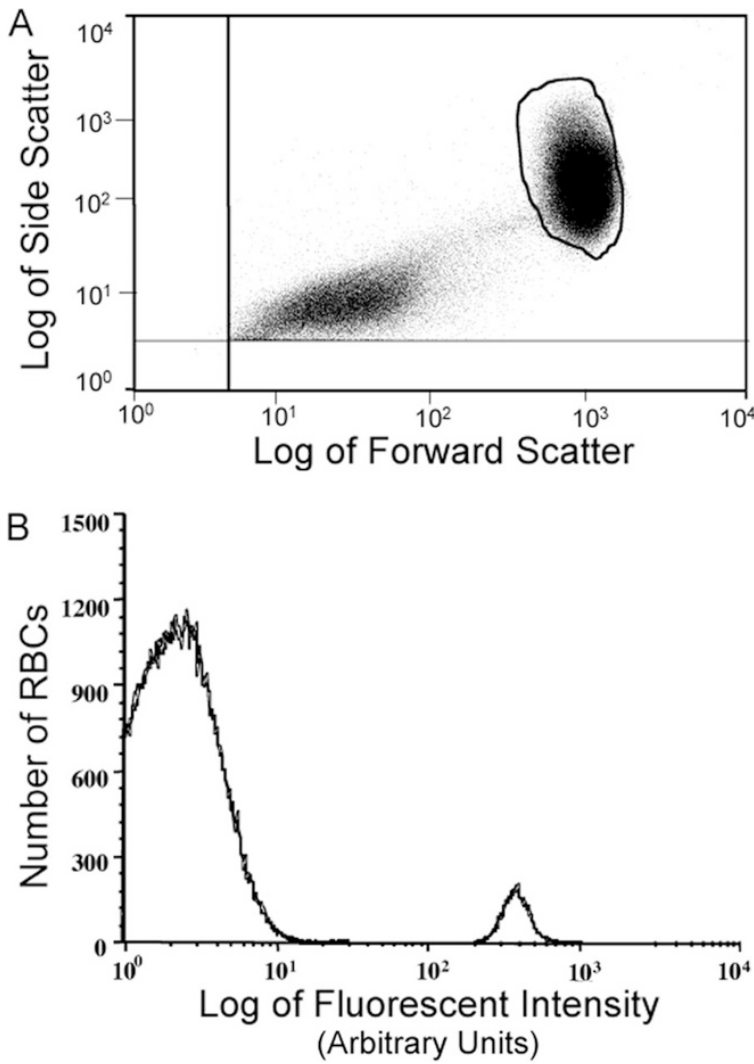

Figure 1. Flow cytometric results for a mixture of unlabeled RBCs and biotin-labeled RBCs from a representative sample. Panel A: Enumeration of RBCs. The selected region (closed loop) includes unlabeled and labeled RBCs but excludes photomultiplier noise, platelets, and any cellular fragments (left lower quadrant). Panel B: Histogram of unlabeled RBCs (large peak) and labeled RBCs (small peak) complexed with fluorescein-conjugated avidin reveals a complete separation between labeled and unlabeled RBCs allowing unambiguous enumeration. 
RCV determination by $\left({ }^{14} \mathrm{C}\right)$ cyanate, ${ }^{51} \mathrm{Cr}$, and $\left({ }^{125} \mathrm{I}\right)$ streptavidin. For each sample of blood obtained after infusion of the labeled RBCs, radioactivity per $\mathrm{mL}$ of blood was calculated and was plotted versus time. The $y$ axis intercept for the linear regression from blood samples drawn between 2 and $30 \min (n=4$ or 5$)$ was estimated. Blood volume (BV) was calculated according to the dilution principle (17) as detailed in Appendix (online at www.pedresearch.org). RCV was calculated as RCV $=\mathrm{BV} \times \mathrm{HCT}$.

Sequential determination of $\boldsymbol{R C V}$. We have previously validated the sequential measurement of RCV in sheep by both $\left({ }^{14} \mathrm{C}\right)$ cyanate and ${ }^{51} \mathrm{Cr}(12)$. To validate the use of biotin-labeled RBCs to measure RCV sequentially in vivo, we conducted sequential studies in three sheep to test the biotin method under three separate conditions: (1) an interval of at least $24 \mathrm{~h}$ between infusion; (2) an interval of only a few minutes between infusions; and (3) three infusions, each separated by at least a day. For each of these three studies, separate aliquots of sheep RBCs were labeled with $\left({ }^{14} \mathrm{C}\right)$ cyanate, ${ }^{51} \mathrm{Cr}$, and biotin on day 0 ; these were mixed and a volume of the labeled blood equal to approximately $1 \%$ of the estimated blood volume was infused. Blood was sampled, and RCV was calculated for each method as described above. At the time of the second measurement, a baseline blood sample was drawn to correct for residual radioactivity using the equation previously published (12) (See Appendix, online at www.pedresearch.org). Then an equal volume of the same mixture of labeled RBCs was infused (approximately doubling the concentration of circulating radioactivity), and RCV was determined as described above a second time. In the third sheep, studies on day 0 and 1 were conducted as described. On day 2, a 4-fold volume of original mixture of labeled RBCs was infused (again doubling the concentration of circulating labels), and RCV was determined a third time.

Statistical analysis. Statistical analyses were performed with StatView software (Abacus Concepts, Berkeley, CA). RCV results are expressed as mean $\pm 1 \mathrm{SD}$ of the analytical replicates. Agreement between biotin and the reference methods was assessed by the correlation coefficient. The pairs of values generated by any two methods (e.g., biotin and flow cytometry versus. ${ }^{51} \mathrm{Cr}$ ) were subjected to linear regression for all animals in which measurements were made (each animal is an independent observation set). The regression line was assessed by determining whether the 95\% confidence intervals for the slope of the regression line incorporated 1 and whether the $95 \%$ confidence interval for the intercept of the regression line incorporated 0 . If both conditions were met, the regression line was deemed not significantly different from a line of identity.

\section{RESULTS}

Determination of red blood cell volume by multiple methods: pair-wise comparisons. RCV was determined simultaneously in the same sheep using at least one of the biotin techniques and at least one of the reference methods. The number of animals varied with the pair of methods. Pair-wise plots are provided in Figure 2, Panels $A-E$, and data for the regressions for each pair are provided in Table 1. These pair-wise comparisons of the RCV values demonstrated close agreement for all method comparisons. The correlation coefficients of all pair-wise regressions were highly significant $(p<0.001)$ and ranged from 0.85 to 0.97 . All 95\% confidence intervals for the regression slopes encompassed 1; all $95 \%$ confidence intervals for $y$ axis intercepts included zero. This indicates that there were no significant differences in any of the paired method comparisons.

Sequential red blood cell volume determinations. RCV was determined sequentially in vivo by the biotin method using both quantitation techniques as well as by the two reference methods, $\left({ }^{14} \mathrm{C}\right)$ cyanate and ${ }^{51} \mathrm{Cr}$. In any given animal at least three methods and usually all four were applied simultaneously in the same animal. RCV values demonstrated close agreement among the four methods (Table 2). With the exception of ${ }^{51} \mathrm{Cr}$, all measurements were well within the empirical analytic variability of $\pm 5 \%$. For ${ }^{51} \mathrm{Cr}$, the mean error versus $\left({ }^{14} \mathrm{C}\right)$ cyanate was only slightly higher at $6.9 \% \pm$ $2 \%$. Thus, the mean RCV estimate is more than 2 standard
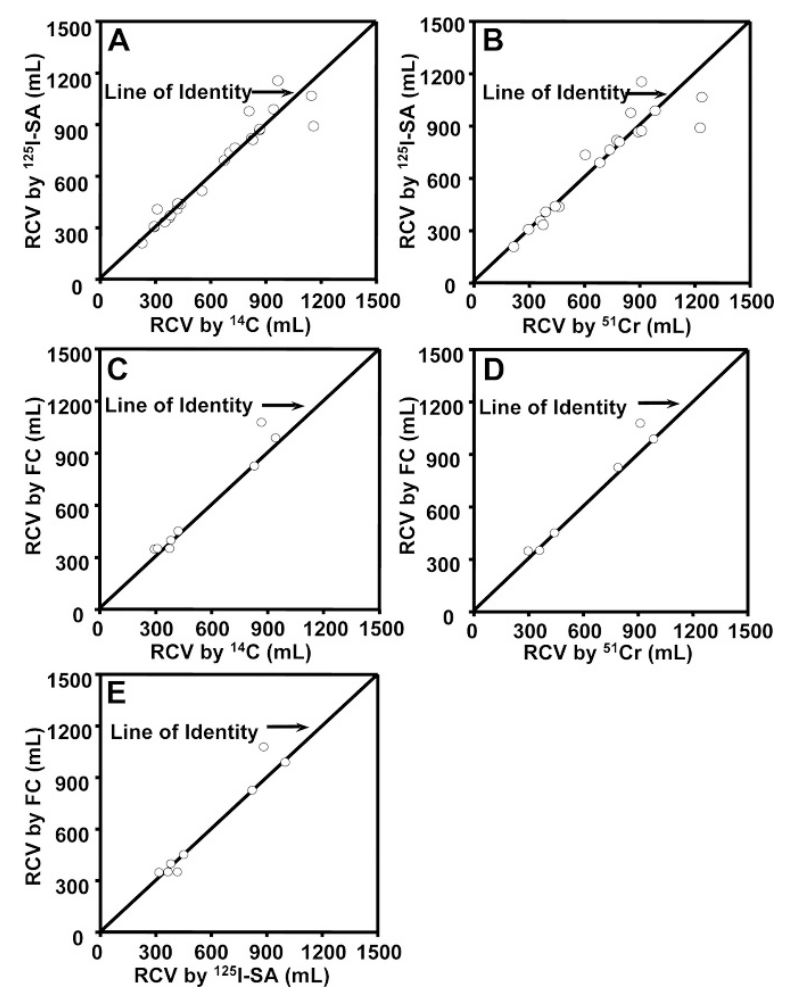

Figure 2. Pair-wise comparisons of different methods for determining RCV in the same sheep. A, Biotin method with $\left({ }^{125} \mathrm{I}\right)$ streptavidin $\left({ }^{125} \mathrm{I}-\mathrm{SA}\right)$ detection vs. $\left({ }^{14} \mathrm{C}\right)$ cyanate $\left({ }^{14} \mathrm{C}\right)$ method in $n=23$ sheep. The correlation coefficient of the regression line was $0.95 . B$. Biotin method with ${ }^{125} \mathrm{I}-\mathrm{SA}$ detection vs. ${ }^{51} \mathrm{Cr}$ method in $n=19$ sheep. The correlation coefficient of the regression line was 0.85 . C. Biotin method with flow cytometric (FC) enumeration $v s$. $\left({ }^{14} \mathrm{C}\right)$ in $n=8$ sheep. The correlation coefficient of the regression line was 0.96. D. Biotin method with FC enumeration $v s .{ }^{51} \mathrm{Cr}$ method in $n=6$ sheep. The correlation coefficient of the regression line was 0.97. E. Biotin method with ${ }^{125} \mathrm{I}$-SA detection $v s$. biotin method with FC enumeration in $n=8$ sheep. The correlation coefficient of the regression line was 0.95 . For all panels, error bars for analytical triplicates are consistently less than the symbol size.

deviations greater than 0 . This small difference even if reproducible (6.9\%) is not likely to be of clinical importance.

\section{DISCUSSION}

The studies presented here indicate that determination of $\mathrm{RCV}$ in sheep by the biotin method with either $\left({ }^{125} \mathrm{I}\right)$ streptavidin quantitation or with flow cytometric enumeration is equivalent to determination of RCV by either of the two reference methods: the $\left({ }^{14} \mathrm{C}\right)$ cyanate method or ${ }^{51} \mathrm{Cr}$ method, which is the standard reference method for RCV in humans (18). The average correlation coefficient was $>0.93$, indicating strong agreement among the methods. To our knowledge, the studies presented here are the first validations of a biotin method for RCV determination against the $\left({ }^{14} \mathrm{C}\right)$ cyanate and ${ }^{51} \mathrm{Cr}$ reference methods in sheep. The successful validation of this biotin method adds another tool for investigation of erythropoiesis and RBC kinetics in an animal model that is applicable in humans. The validation against $\left({ }^{14} \mathrm{C}\right)$ cyanate is likely to be particularly valuable because $\left({ }^{14} \mathrm{C}\right)$ cyanate can also be used to measure RCB survival in vivo in sheep, unlike ${ }^{51} \mathrm{Cr}$ (rapid elution in sheep) and ${ }^{99 \mathrm{~m}} \mathrm{Tc}$ (short half life). For 
Table 1. Comparison of correlation coefficient, regression slope and intercept, and group mean RCV per $\mathrm{kg}$ for pairs of methods for determining $R C V$

\begin{tabular}{|c|c|c|c|c|c|c|c|}
\hline \multirow{2}{*}{$\begin{array}{c}\text { Pair-wise } \\
\text { comparison of RBC } \\
\text { labeling methods }\end{array}$} & \multirow[b]{2}{*}{$N$} & \multirow[b]{2}{*}{$r$} & \multirow{2}{*}{$\begin{array}{l}\text { Regression } \\
\text { slope } \\
(95 \% \mathrm{CI})^{*}\end{array}$} & \multirow{2}{*}{$\begin{array}{l}\text { Regression Y-intercept } \\
(95 \% \mathrm{CI})^{*}\end{array}$} & \multicolumn{2}{|c|}{$\mathrm{RCV}(\mathrm{mL} / \mathrm{kg})$} & \multirow[b]{2}{*}{ Mean weight of sheep ( $\mathrm{kg})$ (range) } \\
\hline & & & & & ${ }^{125} \mathrm{I}-\mathrm{SA}$ & ${ }^{14} \mathrm{C}$ & \\
\hline${ }^{125} \mathrm{I}-\mathrm{SA}$ vs. ${ }^{14} \mathrm{C}$ & 23 & 0.95 & $0.95(0.82-1.00)$ & $+48(-43-+139)$ & $19.0 \pm 4.1$ & $18.4 \pm 3.8$ & $34.3(10.9-65.9)$ \\
\hline${ }^{125} \mathrm{I}-\mathrm{SA} v s .{ }^{51} \mathrm{Cr}$ & 19 & 0.85 & $0.88(0.69-1.06)$ & $+93(-45-+233)$ & $19.3 \pm 4.2$ & $18.8 \pm 3.9$ & $36.6(10.9-65.9)$ \\
\hline FC vs. ${ }^{125} \mathrm{I}-\mathrm{SA}$ & 8 & 0.96 & $1.11(0.69-1.06)$ & $-2(-143-+139)$ & $16.4 \pm 2.6$ & $15.1 \pm 3.4$ & $36.8(18.6-65.9)$ \\
\hline $\mathrm{FC} v s .{ }^{51} \mathrm{Cr}$ & 6 & 0.97 & $1.09(0.81-1.36)$ & $+0.3(-186-+186)$ & $16.9 \pm 2.9$ & $15.6 \pm 3.2$ & $40.6(18.6-65.9)$ \\
\hline $\mathrm{FC} v s .{ }^{125} \mathrm{I}-\mathrm{SA}$ & 8 & 0.95 & $1.11(0.86-1.37)$ & $-35(-195-+126)$ & $15.9 \pm 3.1$ & $16.4 \pm 2.6$ & $36.8(18.6-65.9)$ \\
\hline
\end{tabular}

* Because all regression slope and Y-intercept confidence intervals include 1 and 0 respectively; none of the regression lines was significantly different from a line of identity.

${ }^{14} \mathrm{C},\left({ }^{14} \mathrm{C}\right)$ cyanate; FC, flow cytometry; ${ }^{125} \mathrm{I}-\mathrm{SA},\left({ }^{125} \mathrm{I}\right)$ streptavidin.

Table 2. Sequential volume determinations by multiple techniques

\begin{tabular}{|c|c|c|c|c|c|c|c|c|}
\hline \multirow[b]{2}{*}{ Sheep identity and weight } & \multirow[b]{2}{*}{ Time } & \multicolumn{4}{|c|}{$\mathrm{RCV}(\mathrm{mL})$} & \multicolumn{3}{|c|}{ Difference from ${ }^{14} \mathrm{C}$} \\
\hline & & ${ }^{14} \mathrm{C}$ & ${ }^{51} \mathrm{Cr}$ & ${ }^{125} \mathrm{I}-\mathrm{SA}$ & $\mathrm{FC}$ & ${ }^{51} \mathrm{Cr}$ & ${ }^{125} \mathrm{I}-\mathrm{SA}$ & $\mathrm{FC}$ \\
\hline 1 & 0 & 346 & 370 & 338 & ND & $6.9 \%$ & $-2.3 \%$ & ND \\
\hline $26.4 \mathrm{~kg}$ & Day 2 & 331 & 363 & 313 & ND & $9.7 \%$ & $-5.4 \%$ & ND \\
\hline Difference from time 0 value & - & $-4.3 \%$ & $-1.9 \%$ & $-7.4 \%$ & - & - & - & - \\
\hline 2 & 0 & 417 & 436 & 446 & 457 & $4.6 \%$ & $7.0 \%$ & $9.6 \%$ \\
\hline \multirow[t]{2}{*}{$36.8 \mathrm{~kg}$} & $20 \mathrm{~min}$ & 425 & 462 & 473 & 492 & $8.7 \%$ & $11.3 \%$ & $15.8 \%$ \\
\hline & - & $1.9 \%$ & $6.0 \%$ & $6.1 \%$ & $7.7 \%$ & - & - & - \\
\hline 3 & 0 & 938 & 979 & 994 & 994 & $4.4 \%$ & $6.0 \%$ & $6.0 \%$ \\
\hline $60.5 \mathrm{~kg}$ & Day 1 & 903 & 952 & 880 & 917 & $5.4 \%$ & $-2.5 \%$ & $1.6 \%$ \\
\hline \multirow[t]{2}{*}{ Difference from time 0 value } & - & $-3.7 \%$ & $-2.8 \%$ & $-11.0 \%$ & $-7.7 \%$ & - & - & - \\
\hline & Day 2 & 934 & 1013 & 1025 & 1030 & $8.5 \%$ & $9.7 \%$ & $10.3 \%$ \\
\hline \multirow[t]{3}{*}{ Difference from time 0 value } & - & $-0.43 \%$ & $3.5 \%$ & $3.1 \%$ & $3.6 \%$ & - & - & - \\
\hline & - & - & - & - & Average error & $6.9 \%$ & $3.4 \%$ & $8.7 \%$ \\
\hline & - & - & - & - & SD of error & $2.1 \%$ & $6.7 \%$ & $5.3 \%$ \\
\hline
\end{tabular}

${ }^{14} \mathrm{C},\left({ }^{14} \mathrm{C}\right)$ cyanate; FC, flow cytometry; ${ }^{125} \mathrm{I}-\mathrm{SA},\left({ }^{125} \mathrm{I}\right)$ streptavidin; ND, not determined.

brevity, only the comparisons of results versus $\left({ }^{14} \mathrm{C}\right)$ cyanate are discussed hereafter.

The biotin method with either quantitation technique is particularly suitable for use in fetuses, infants, children, and pregnant women for whom infusion of a radioactive compound is not required. Flow cytometric enumeration of biotinlabeled RBCs is superior to $\left({ }^{125} \mathrm{I}\right)$ streptavidin quantitation in three important respects. First, flow cytometric enumeration for RCV determination can be performed on as little as $20 \mu \mathrm{L}$ of blood. Second, ex vivo use of ${ }^{125} \mathrm{I}$, an intermediate-lived isotope is avoided. Third, the biotin flow cytometric enumeration method is not susceptible to artifacts arising from either dilution ("squeezing") or concentration ("sludging") in obtaining venous/capillary blood samples after infusing the labeled RBCs $(13,14)$ because flow cytometric enumeration depends upon labeled RBCs as a percent of total RBCs rather than as a concentration of label in the blood sample. In contrast, the biotin method using the $\left({ }^{125} \mathrm{I}\right)$ streptavidin technique measures the blood concentration of the RBC label and, thus, is analogous to determination of RCV by ${ }^{51} \mathrm{Cr}$, ${ }^{99 \mathrm{~m}} \mathrm{Tc}$, and $\left({ }^{14} \mathrm{C}\right)$ cyanate. For example, all methods that are dependent on blood concentration measurements are susceptible to squeeze and sludge artifacts.

The conclusions for the RCV determined by the biotin method with flow cytometric enumeration are based on only about a third as many animals as the $\left({ }^{125} \mathrm{I}\right)$ streptavidin technique; in this sense, the conclusions are limited. Yet, the regression coefficients for the flow cytometry data are actually greater than the $\left({ }^{125} \mathrm{I}\right)$ streptavidin data. We speculate that this reflects the robustness of flow cytometric enumeration. The first and the third of these three advantages are particularly important for the feasibility of application of the biotin method to human neonates.

In addition to the excellent agreement of the biotin method relative to $\left({ }^{14} \mathrm{C}\right)$ cyanate, our results are in good agreement with absolute RCV normalized by body weight reported for sheep by other investigators (15). RCV per kg body weight was $19.0 \pm 4.1$ for the biotin method with the $\left({ }^{125} \mathrm{I}\right)$ streptavidin technique ( $n=23$ sheep) and $16.4 \pm 2.6$ for the biotin method with the flow cytometric technique ( $n=8$ sheep). Using autologous RBCs labeled with both ${ }^{59} \mathrm{Fe}$ and ${ }^{51} \mathrm{Cr}$, Wade and Sasser reported RCV of $21.1 \pm 2.2 \mathrm{~mL} / \mathrm{kg}$ (15). These differences likely reflected differences in the weight of the sheep studied.

In determining $\mathrm{RBC}$ production, the ability to determine $\mathrm{RCV}$ at several intervals that are short compared with the lifetime of the RBCs would be useful. This capability would be particularly useful in distinguishing $\mathrm{RBC}$ production from dilution by blood volume expansion associated with somatic growth and in situations in which an intervening transfusion is required or in which $\mathrm{RBC}$ loss due to hemorrhage or other blood loss occurs. When using long-lived RBC labels such as $\left({ }^{14} \mathrm{C}\right)$ cyanate and biotin, residual concentrations of labeled RBCs from previous studies will confound repeat studies. We report here sequential measurements of RCV determined independently by $\left({ }^{14} \mathrm{C}\right)$ cyanate, ${ }^{51} \mathrm{Cr}$, and biotin. Our correction equation predicts accurate results could be achieved by dou- 
bling of the volume of labeled RBCs infused with each successive measurement, which achieves a reasonable increment in blood concentration of radioactivity above baseline (See Appendix online at www.pedresearch.org for derivation). That conclusion was confirmed empirically by several in vitro dilution experiments that explored the characteristics of correcting for baseline radioactivity (data not shown). The current in vivo sheep studies indicate that the 4 values agree well with each other after the residual label from previous studies is accurately corrected by our equation. We conclude that, with successive doubling of the number of biotinylated RBCs infused, multiple sequential in vivo measurements can be made using either biotin quantitation technique.

In summary, the present data provide strong evidence that circulating RCV can be accurately measured in sheep using biotin-labeled RBCs with either $\left({ }^{125} \mathrm{I}\right)$ streptavidin or flow cytometric quantitation techniques. This study also provides evidence that accurate sequential measurements of RCV can be made in the same sheep using either technique for quantitation of a biotin label. Based on the utility of the ovine model as a surrogate for studies of fetal and newborn infants, the biotin RBC method is likely to prove useful in addressing questions of relevance during the neonatal period in humans.

\section{REFERENCES}

1. Brugnara C 2003 The neonatal erythrocyte and its disorder. In: Nathan D, Ginsburg D, Orkin S (eds) Nathan and Oski's Hematology of Infancy and Childhood. Philadelphia: W.B. Saunders Company, Inc., pp 19-55

2. Fanaroff AA, Stoll BJ, Wright LL, Carlo WA, Ehrenkranz RA, Stark AR, Bauer CR, Donovan EF, Korones SB, Laptook AR, Lemons JA, Oh W, Papile LA, Shankaran S, Stevenson DK, Tyson JE, Poole WK, NICHD Neonatal Research Network 2007 Trends in neonatal morbidity and mortality for very low birthweight infants. Am J Obstet Gynecol 196:147
3. Faxelius G, Raye J, Gutberlet R, Swanstrom S, Tsiantos A, Dolanski E, Dehan M, Dyer N, Lindstom D, Brill AB, Stahlman M 1977 Red cell volume measurements and acute blood loss in high-risk newborn infants. J Pediatr 90:273-281

4. Price DC, Swann SJ, Hung ST, Kaufman L, Huberty JP, Shohet SB 1976 The measurement of circulating red cell volume using non-radioactive cesium and fluorescent excitation anaylsis. J Lab Clin Med 87:535-543

5. Mock DM, Lankford GL, Widness JA, Burmeister LF, Kahn D, Strauss RG 1999 Measurement of circulating red blood cell volume using biotin labeled red cells: validation against ${ }^{51} \mathrm{Cr}$ labeled red cells. Transfusion 39:149-155

6. Strauss RG, Mock DM, Johnson K, Mock NI, Cress G, Knosp L, Lobas L, Schmidt RL 2003 Circulating RBC volume, measured with biotinylated RBCs, is superior to the Hct to document the hematologic effects of delayed versus immediate umbilical cord clamping in preterm neonates. Transfusion 43:1168-1172

7. Mock DM, Lankford GL, Widness JA, Burmeister LF, Kahn D, Strauss RG 2004 RBCs labeled at two biotin densities permit simultaneous and repeated measurements of circulating RBC volume. Transfusion 44:431-437

8. Brace RA 1984 Blood volume in the fetus and methods for its measurement. In: Nathanielsz PW (ed) Animal Models in Fetal Medicine. Ithaca: Perinatology Press, pp 19-36

9. Widness JA, Lowe LS, Bell EF, Mock DM, Kistard JA, Bard H 2000 Adaptive responses during anemia and its correction in lambs. J Appl Physiol 88:1397-1406

10. Moritz KM, Lim GB, Wintour EM 1997 Developmental regulation of erythropoietin and erythropoiesis. Am J Physiol 273:R1829-R1844

11. Blunt M, Huisman T 1975 The Hemoglobins of Sheep. The Blood of Sheep: Composition and Function. New York: Springer-Verlag

12. Mock DM, Lankford GL, Burmeister LF, Strauss RG 1997 Circulating red cell volume and red cell survival can be accurately determined in sheep using the $\left[{ }^{14} \mathrm{C}\right]$ cyanate label. Pediatr Res 41:916-921

13. Rivera LM, Rudolph N 1982 Postnatal persistence of capillary-venous differences in hematocrit and hemoglobin values in low-birth-weight and term infants. Pediatrics 70:956-957

14. Linderkamp O, Versmold HT, Strohhacker I, Messow-Zahn K, Riegel KP, Betke K 1977 Capillary-venous hematocrit differences in newborn infants. I. Relationship to blood volume, peripheral blood flow, and acid base parameters. Eur J Pediatr 127:9-14

15. Wade L Jr, Sasser LB 1970 Body water, plasma volume, and erythrocyte volume in sheep. Am J Vet Res 31:1375-1378

16. Mock DM, Strauss RG, Lankford GL $1997{ }^{14}$ C-cyanate labeling of sheep red cells: covalent binding to hemoglobin continues in vivo for a day. Pediatr Res 41:424-429

17. 1973 Standard techniques for the measurement of red-cell and plasma volume. A report by the International Committee for Standardization in Hematology (ICSH): Panel on Diagnostic Applications of Radioisotopes in Haematology. Br J Haematol 25:801-814

18. Brace RA 1983 Blood volume and its measurement in the chronically catheterized sheep fetus. Am J Physiol 244:H487-H494 